\title{
How small-scale variation in oyster reef patchiness influences predation on bivalves
}

\author{
Peter I. Macreadie ${ }^{1,2, *}$, Nathan R. Geraldi ${ }^{1}$, Charles H. Peterson ${ }^{1}$ \\ ${ }^{1}$ Institute of Marine Sciences, University of North Carolina at Chapel Hill, Morehead City, North Carolina 28557, USA \\ ${ }^{2}$ School of the Environment, University of Technology, Sydney 2007, New South Wales, Australia
}

\begin{abstract}
As oyster fishing continues to degrade reef habitat along the US Atlantic coast, oyster reefs appear increasingly fragmented on small spatial scales. In outdoor mesocosms, experiments tested how consumption of representatives of 4 different bivalve guilds by each of 3 mesopredators varies between continuous and fine-scale patches of oyster reef habitat. The mesopredator that fed least (stone crab) exhibited no detectable change in consumption on any bivalve (ribbed mussel, bay scallop, hard clam, and 3 size classes of eastern oyster). Consumption of bay scallops by both blue crabs and sheepshead fish was greater in small patches than in continuous oyster reef habitat. Of the bivalve guilds tested, only the scallop possesses swimming motility sufficient to reduce predation, an escape response that would likely leave the bivalve protected within structured habitat in larger continuous oyster reefs. Sheepshead consumed more small oysters in the continuous habitat than in the fine patches, while no other predator-prey interaction exhibited differential feeding as a function of habitat patchiness. Consequently, predation by mesopredators on bivalves can vary with the scale of oyster reef patchiness, but this process may depend upon the bivalve guild. Understanding the role of habitat patchiness on fine scales may be increasingly important in view of the declines in apex predatory sharks leading to mesopredator release, and global climate change directly and indirectly enhancing stone crab abundances, thereby increasing potential predation on bivalves.
\end{abstract}

KEY WORDS: Habitat fragmentation · Predator-prey interactions · Oyster reefs · Bivalve guild · Scallop

Resale or republication not permitted without written consent of the publisher

\section{INTRODUCTION}

Distribution and abundance of animals often vary between patchy and more continuous habitat (e.g. Didham et al. 1998, Laurance et al. 1998, Macreadie et al. 2009), and efforts are intensifying to understand the mechanisms that cause these differences (Cronin 2009, Warry et al. 2009). In coastal marine benthic communities, predation is widely recognized to be a key determinant of the distribution and abundance of prey (e.g. Paine 1966, Dayton 1971), yet few empirical experiments have addressed how changing habitat patchiness affects predator-prey interactions (but see Hovel \& Lipcius 2001, Hovel 2003). Recent research in seagrass systems demonstrates that some mesopredators alter their distribution in response to how habitat fragmentation influences on prey (Macreadie et al. 2010), but it is not yet clear how widespread such responses are and whether they are accompanied by significant shifts in the composition or amount of prey consumed.

Our goal was to assess whether prey consumption by mesopredators is affected by changing habitat patchiness at fine scales. We used estuarine oyster reef habitat as our experimental system because: (1) oyster reefs are increasingly degraded by bottom-disturbing fishing gear along the US east coast (DeAlteris 1988, Rothschild et al. 1994, Lenihan \& Peterson 1998, Smith et al. 2005) and elsewhere around the world (Beck et al. 2011); (2) such intense disturbance by dredges, tongs, and rakes has fragmented the habitat and created smaller patches (Lenihan \& Micheli 1999, Lenihan \& Peterson 2004, C. H. Peterson pers. obs.); (3) oyster reefs support production of many economically important fish and shellfish (e.g. Coen et al. 1999, Lenihan et 
al. 2001, Peterson et al. 2003); and (4) oyster reefs are now known for the importance of multiple cascading consequences of changes in predators, habitat structure, and their interactions (Grabowski 2004, Grabowski et al. 2008, Kimbro et al. 2009). For our experimental tests in controlled laboratory mesocosms, we chose 3 reef-associated mesopredators, the blue crab Callinectes sapidus, stone crab Menippe mercenaria, and sheepshead Archosargus probatocephalus, and representatives of 4 taxonomically and functionally different bivalve prey, the ribbed mussel Geukensia demissa, hard clam Mercenaria mercenaria, bay scallop Argopecten irradians, and eastern oyster Crassostrea virginica. We compared prey consumption by mesopredators between continuous and patchy oyster reef habitat to test the hypotheses that the amounts and/or composition of prey consumed vary with habitat configuration on a small scale and that predation differences between continuous and patchy habitat vary among representatives of different prey guilds.

\section{MATERIALS AND METHODS}

Experiments were conducted at the University of North Carolina's Institute of Marine Sciences (Morehead City, NC) during July 2009 in 8 outdoor concrete mesocosms ( $4 \mathrm{~m}$ long $\times 3 \mathrm{~m}$ wide $\times 0.6 \mathrm{~m}$ deep) continuously supplied with unfiltered seawater $\left(\sim 1 \mathrm{l} \mathrm{s}^{-1}\right)$ from nearby Bogue Sound. We covered mesocosm floors with a $\sim 1 \mathrm{~cm}$ layer of muddy sediment. To test the effects of habitat patchiness on mesopredator foraging, we installed oyster reef habitat in 2 configurations: single $0.75 \times 0.75 \mathrm{~m}$ patch of oyster shell (hereafter 'continous') and nine $0.25 \times 0.25 \mathrm{~m}$ patches of oyster shell (hereafter 'patchy'). These scales of patchiness are consistent with field observations of apparently increasing small-scale patchiness of fished oyster reefs (C. H. Peterson pers. obs.). Both habitat configurations held the same total volume (37.9 l) and area of loose shells of large oysters, differing only in spatial arrangement. We decided to employ uncemented, largely horizontally oriented oyster shells to mimic the present condition of most remaining oyster reefs, which have been modified by intense fishing pressure (Lenihan \& Micheli 1999).

The 3 mesopredators and 4 bivalve prey we collected from Bogue Sound are common in oyster reef habitat (Peterson et al. 2003). Adult blue crabs (carapace width, mean $\pm \mathrm{SE}: 136 \pm 2.2 \mathrm{~mm}, \mathrm{n}=16$, all female) and stone crabs (106 $\pm 2.6 \mathrm{~mm}, \mathrm{n}=16$, all male) were collected in crab pots, and sheepshead (standard length, mean $\pm \mathrm{SE}: 40 \pm 2.6 \mathrm{~cm}$, wet weight: $1.8 \pm$ $0.3 \mathrm{~kg}, \mathrm{n}=16$ ) in pound nets. Mesopredators were held for 1 to 4 wk in laboratory holding tanks in flow- through seawater and fed rations of frozen fish every $2 \mathrm{~d}$ prior to experiments. Prey chosen represent different guilds of bivalves: 'semi-infaunal bysally attached' ribbed mussels (12 to $22 \mathrm{~mm}$ shell size, viz. distance from the umbo to the farthest edge on the opposite side of the shell), 'infaunal' hard clams (11 to $16 \mathrm{~mm}$ ), 'mobile swimming' bay scallops (45 to $64 \mathrm{~mm}$ ), and 3 size classes of 'epifaunal sessile' eastern oysters (small: 14 to $30 \mathrm{~mm}$; medium: 31 to $50 \mathrm{~mm}$; and large: 51 to $76 \mathrm{~mm}$ ). Prey items were added to each oyster reef habitat treatment by placing them on the oyster shell in quantities (63 mussels, 27 clams, 6 scallops, 9 small oysters, 6 medium oysters, 3 large oysters) of approximately equal total prey biomass. As much as possible, prey were evenly distributed across the continuous treatments and over the 9 small patches in the patchy treatments. Mussels were added in clumps of 7 individuals, with each clump formed by inducing byssal attachment to the inside of a single large oyster shell. Clams were distributed among and then burrowed into the loose oyster shells. Scallops were positioned within the oyster shell habitat and remained on the surface. Oysters were glued to the inside of oyster shells $(3,2$, and 1 individual per shell for small, medium, and large oysters, respectively) to mimic natural conditions. Densities of bivalves fall within naturally occurring abundances for the size ranges used (Micheli \& Peterson 1999, Grabowski et al. 2005, P. I. Macreadie pers. obs.).

The experimental design involved haphazardly assigning continuous oyster habitat to 4 mesocosms and patchy habitat to the remaining 4 , establishing identical prey fields of the 6 prey types in every mesocosm, and then creating the predator treatments necessary to complete a set of all combinations of 2 habitat configurations and 4 predator treatments (single individuals of each predator species plus a treatment with one of each predator combined). Mesopredators were introduced to mesocosms for $24 \mathrm{~h}$, and then removed while tanks drained and the oyster shell was taken out to count surviving prey accurately and thus infer consumption. This experiment was repeated in 4 replicate trials of each set of treatments. We observed mesopredator and prey behaviors repeatedly during the entire daylight period of each trial. Blocking by trial (date) allowed us to pair continuous and patchy treatments and apply paired $t$-tests to evaluate how habitat configuration affected consumption of each prey type in each predator treatment (Quinn \& Keough 2002). In addition, we identified any significant differences in composition of prey consumed between continous and patchy habitats using analysis of similarity (ANOSIM) permutation tests based on Bray-Curtis dissimilarities (Clarke 1993). Assumptions of normality were confirmed using box plots and plots of variance. 


\section{RESULTS}

Each mesopredator consumed all 4 prey species and all 6 prey types, with highest prey consumption by sheepshead $(50 \%$ of prey offered), followed by blue crab (37\%) and stone crab (12\%). Total prey consumption in the 3-mesopredator treatment was approximately $46 \%$. The paired $t$-tests detected 3 cases (including a marginally significant result of $p=0.061$ ) in which prey consumption by an individual mesopredator differed between habitat configurations (Table 1). Blue crabs consumed $60 \%$ of scallops in patchy oyster habitat but not a single scallop in continuous habitat, whereas sheepshead similarly consumed more scallops in patchy $(79 \%)$ than in continuous (22\%) habitat (Fig. 1). In contrast, sheepshead consumed more small oysters in continuous $(68 \%)$ than in patchy $(40 \%)$ oyster habitat (Fig. 1). We detected no effect of habitat configuration for stone crabs or in the 3-species combination of predators (Table 1). ANOSIM detected no difference in the composition of prey consumed between patchy and continuous habitats for any of the 4 mesopredator treatments (Table 1).

Behaviors observed during the experiments provided insights into mechanisms of interactions among mesopredators, oyster habitat, and prey. Scallops, the only mobile swimming prey, moved regularly in the patchy configuration, but remained where initially placed in continuous oyster reef habitat. Blue crabs often transported and then consumed prey bivalves on sediment away from oyster reef habitat. Stone crabs usually buried within the oyster shell or in the corners of the mesocosms; however, just after initial introduction, they moved extensively throughout each mesocosm. Sheepshead disturbed
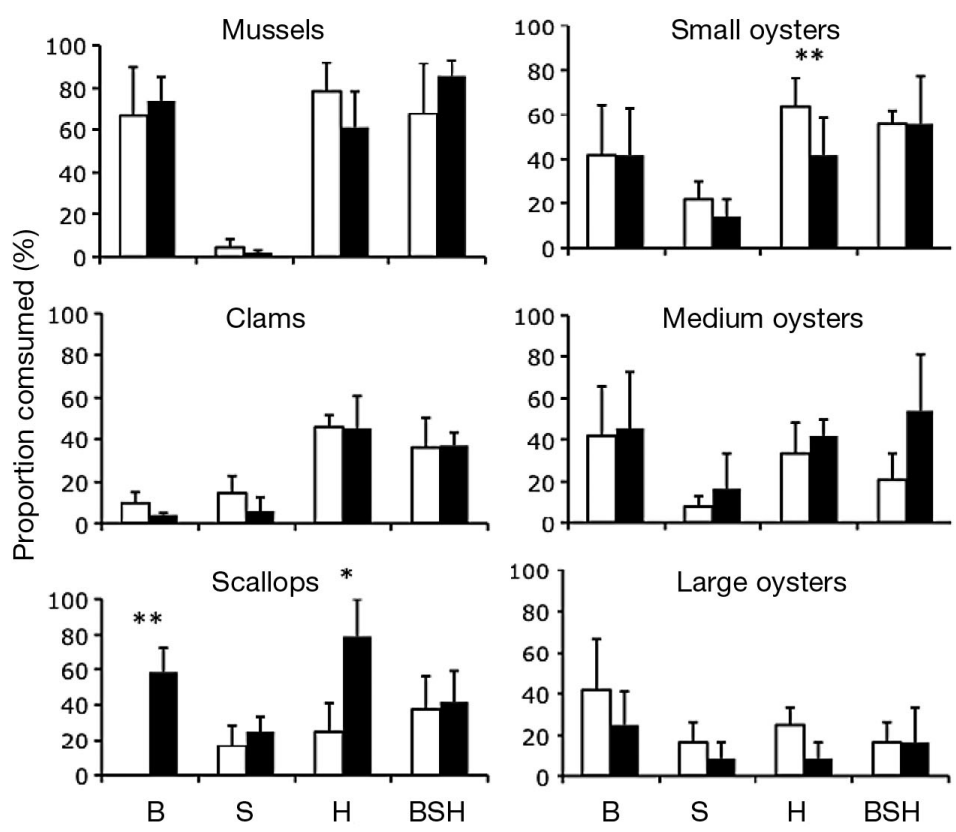

Fig. 1. Amounts and composition of prey consumed by estuarine mesopredators (B: blue crab; S: stone crab; $\mathrm{H}$ : sheepshead) in continuous (white bars) and patchy (black bars) oyster reef habitat configurations. Data represent the mean $( \pm \mathrm{SE}, \mathrm{n}=4)$ percentage $(\%)$ of prey consumed by a single, individual mesopredator in isolation, and by a combination of 1 of each predator (BSH). ${ }^{* *}$ indicates a significant difference $(p<0.05)$ in consumption between habitat configurations according to paired $t$-tests, and * indicates a marginally significant difference $(0.05<\mathrm{p}<0.10)$

habitat patches, scattering oyster shell across the mesocosm; this behavior was particularly prevalent in continuous habitat and appeared to be associated with foraging for prey regardless of whether the sheepshead was solitary or combined with the other mesopredators. We did not observe any between-species aggressive interactions in the combined mesopredator treatment; mesopredators usually spread as far apart from each other as possible.

Table 1. Statistical tests of whether prey consumption differs between continuous and patchy oyster reef habitat (data presented in Fig. 1). Paired $t$-tests $(\mathrm{df}=3)$ assessed differences in prey consumption for 4 different predator treatments and each of 6 separate prey types, whereas analysis of similarity (ANOSIM) assessed analogous differences in the assemblage composition of prey consumed between the 2 habitat configurations. Bold indicates significant $(\mathrm{p}<0.05)$ and marginally significant $(0.05<\mathrm{p}<0.10)$ differences. Oyster sizes are small (S), medium (M), and large (L)

\begin{tabular}{|c|c|c|c|c|c|c|c|c|c|c|c|c|c|c|}
\hline \multirow[t]{3}{*}{ Predator } & \multicolumn{12}{|c|}{ - Paired $t$-test- } & \multicolumn{2}{|c|}{ —ANOSIM- } \\
\hline & \multicolumn{2}{|c|}{ Mussels } & \multicolumn{2}{|c|}{ Clams } & \multicolumn{2}{|c|}{ Scallops } & \multicolumn{2}{|c|}{ Oysters-S } & \multicolumn{2}{|c|}{ Oysters-M } & \multicolumn{2}{|c|}{ Oysters-L } & \multirow[t]{2}{*}{ Global R } & \multirow[t]{2}{*}{$\mathrm{p}$} \\
\hline & $t$ & $\mathrm{p}$ & $t$ & $\mathrm{p}$ & $t$ & $\mathrm{p}$ & $t$ & $\mathrm{p}$ & $t$ & $\mathrm{p}$ & $t$ & $\mathrm{p}$ & & \\
\hline Blue crab & 0.36 & 0.740 & 1.00 & 0.391 & 4.04 & 0.027 & $<0.01$ & 1.000 & 0.12 & 0.911 & 0.48 & 0.664 & -0.010 & 0.400 \\
\hline Stone crab & 0.52 & 0.641 & 0.81 & 0.478 & 0.42 & 0.703 & 0.68 & 0.547 & 0.58 & 0.604 & 0.52 & 0.638 & 0.083 & 0.657 \\
\hline Sheepshead & 1.08 & 0.361 & 0.05 & 0.962 & 2.93 & 0.061 & 4.90 & 0.016 & 2.32 & 0.103 & 1.73 & 0.182 & 0.135 & 0.200 \\
\hline All 3 predators & 0.66 & 0.554 & 0.05 & 0.967 & 0.26 & 0.809 & $<0.01$ & 1.000 & 0.87 & 0.450 & $<0.01$ & 1.00 & -0.177 & 0.943 \\
\hline
\end{tabular}




\section{DISCUSSION}

Results of our experiments demonstrate that bivalve prey consumption by mesopredators on degraded oyster reefs can vary with changes in the degree of habitat patchiness. Nevertheless, small-scale changes to patchiness of oyster habitat had no effect on many predator treatments. In addition, the absence of significant differences in mesopredator prey consumption between the 2 habitat configurations (despite confirmed differences in consumption of some individual prey types) suggests that changing habitat patchiness did not induce widespread prey switching (Murdoch 1969). The absence of detectable differences between continuous and patchy oyster habitat in stone crab foraging probably arises from low feeding rates by stone crabs, which consumed only $12 \%$ of prey offered. The most compelling patterns of response to habitat configuration were the similar effects of blue crab and sheepshead predation on bay scallops: each of these mesopredators consumed substantially fewer scallops in continuous habitat. This pattern was unique to the scallop. The only other change in prey consumption with habitat configuration reflected the opposite response: consumption of small oysters by sheepshead was greater in continuous oyster reef. The inconsistency in direction of response to habitat fragmentation among bivalve prey from different guilds shows that a generic model of predator-prey response to habitat fragmentation may not apply to bivalves in oyster reef systems, and that accurate predictions of the food web consequences of oyster reef habitat fragmentation require consideration of the identity or the intrinsic characteristics of predators, prey, or both (O'Connor et al. 2008).

Our qualitative observations of mesopredator behavior provide some insight into potential mechanisms underlying differences among prey, and perhaps the guilds they represent, in how habitat patchiness influences their risk of consumption. Scallops are the only mobile swimming bivalve used, and they frequently expressed that mobility in the patchy configuration, possibly increasing their detectability (and predation loss) to blue crabs and sheepshead relative to less active scallops in continuous habitat. In addition, whereas bay scallops swim to escape predation (Peterson et al. 1982) over distances of $0.5 \mathrm{~m}$ (Powers \& Peterson 2000), the spatial scale of those excursions is such that a bay scallop located in a small patch of our reef habitat and induced to swim would be more likely to land outside the protection of structured oyster reef than an analogous swimming scallop departing from continuous habitat. None of the sessile prey types used in our experiments exhibited a pattern of higher predation mortality inside patchier habitat, implying that guild type may be important to how predation risk in bivalves changes with habitat patch size. Supporting field evidence also shows that mobile bivalves experience higher predation in patchy environments (Bologna \& Heck 1999, Clark et al. 2000). Although there is little guidance in the literature to infer possible mechanisms behind changes in sheepshead foraging behavior with habitat patchiness, their strong disturbance of continuous oyster habitat during foraging might have led to higher predation rates on small oysters in continuous than in fine-scale patchy habitat, which they disturbed less. A similar but non-significant pattern of predation risk was also exhibited by mussels, the other prey heavily consumed by sheepshead.

Our choice of mesopredators was based on a desire to use species characteristic of oyster reef habitat and potentially undergoing changes in abundance along the US east coast, with implications for ecologically and economically important bivalves. Expanding numbers of stone crabs in North Carolina may be a consequence of warming estuaries (Micheli et al. 2008) inducing a poleward range shift (Wong et al. 2010), and expanding rock habitat from installation of riprap and other stone structures (Shervette et al. 2004) to protect coastal property from damage under rising sea levels and increasing frequency of intense storms. The dramatic reduction and functional loss of apex predatory sharks along the US east coast (Myers et al. 2007) may also be allowing population growth of mesopredators normally consumed and controlled by sharks. This process of mesopredator release may also apply to sheepshead populations. Blue crab populations vary greatly among years in east coast estuaries, affected by fishing pressure, environmental conditions (Zohar et al. 2008), and probably also by predation from higher-order mesopredators such as red and black drum and striped bass. Consequently, understanding how predation changes with habitat patchiness for each of the 3 mesopredators in our study has relevance to changing dynamics of estuaries.

Acknowledgements. We thank J. Meiners, J. Moore, L. Dee, T. Creech, L. Brown, C. Martin, and W. Rogers for field and laboratory assistance. We are grateful to P. Snelgrove and 3 anonymous reviewers, whose comments and suggestions greatly improved earlier versions of the manuscript. Funding was provided by the National Oceanic and Atmospheric Administration (NOAA) Ecological Effects of Sea Level Rise Program, the North Carolina Coastal Recreational Fishing License (CRFL) Program, and the Cooperative Institute for Coastal and Estuarine Environmental Technology. Partial funding for N.R.G. was provided by a NERRS Graduate Fellowship. Research was done using the facilities of the University of North Carolina Institute of Marine Sciences. 


\section{LITERATURE CITED}

Beck MW, Brumbaugh RD, Airoldi L, Carranza A and others (2011) Oyster reefs at risk and recommendations for conservation, restoration, and management. Bioscience 61:107-116

Bologna PAX, Heck KL (1999) Differential predation and growth rates of bay scallops within a seagrass habitat. J Exp Mar Biol Ecol 239:299-314

Clark ME, Wolcott TG, Wolcott DL, Hines AH (2000) Foraging behavior of an estuarine predator, the blue crab Callinectes sapidus in a patchy environment. Ecography 23:21-31

> Clarke KR (1993) Nonparametric multivariate analyses of changes in community structure. Aust J Ecol 18:117-143

Coen L, Luckenbach MW, Breitberg DL (1999) The role of oyster reefs as essential fish habitat: a review of current knowledge and some new perspectives. In: Benaka LR (ed) Fish habitat: essential fish habitat and rehabilitation. American Fisheries Society, Bethesda, MD, p 438-454

Cronin JT (2009) Habitat edges, within-patch dispersion of hosts, and parasitoid oviposition behavior. Ecology 90: 196-207

> Dayton PK (1971) Competition, disturbance, and community organization-provision and subsequent utilization of space in a rocky intertidal community. Ecol Monogr 41: 351-387

DeAlteris JT (1988) The geomorphic development of Wreck Shoal, a subtidal oyster reef of the James River, Virginia. Estuaries 11:240-249

> Didham RK, Hammond PM, Lawton JH, Eggleton P, Stork NE (1998) Beetle species responses to tropical forest fragmentation. Ecol Monogr 68:295-323

Grabowski JH (2004) Habitat complexity disrupts predatorprey interactions but not the trophic cascade on oyster reefs. Ecology 85:995-1004

Grabowski JH, Hughes AR, Kimbro DL, Dolan MA (2005) How habitat setting influences restored oyster reef communities. Ecology 86:1926-1935

Grabowski JH, Hughes AR, Kimbro DL (2008) Habitat complexity influences cascading effects of multiple predators. Ecology 89:3413-3422

Hovel KA (2003) Habitat fragmentation in marine landscapes: relative effects of habitat cover and configuration on juvenile crab survival in California and North Carolina seagrass beds. Biol Conserv 110:401-412

> Hovel KA, Lipcius RN (2001) Habitat fragmentation in a seagrass landscape: patch size and complexity control blue crab survival. Ecology 82:1814-1829

Kimbro DL, Grosholz ED, Baukus AJ, Nesbitt NJ, Travis NM, Attoe S, Coleman-Hulbert C (2009) Invasive species cause large-scale loss of native California oyster habitat by disrupting trophic cascades. Oecologia 160:563-575

Laurance WF, Ferreira LV, Rankin-De Merona JM, Laurance SG (1998) Rain forest fragmentation and the dynamics of Amazonian tree communities. Ecology 79:2032-2040

Lenihan HS, Micheli F (1999) Biological effects of shellfish harvesting on oyster reefs: resolving a fishery conflict by ecological experimentation. Fish Bull 98:86-95

Lenihan HS, Peterson CH (1998) How habitat degradation through fishery disturbance enhances impacts of hypoxia on oyster reefs. Ecol Appl 8:128-140

Lenihan HS, Peterson CH (2004) Conserving oyster reef habitat by switching from dredging and tonging to diverharvesting. Fish Bull 102:298-305
Lenihan HS, Peterson CH, Byers JE, Grabowski JH, Thayer GW, Colby DR (2001) Cascading of habitat degradation: oyster reefs invaded by refugee fishes escaping stress. Ecol Appl 11:764-782

Macreadie PI, Hindell JS, Jenkins GP, Connolly RM, Keough MJ (2009) Fish responses to experimental fragmentation of seagrass habitat. Conserv Biol 23:644-652

- Macreadie PI, Hindell JS, Keough MJ, Jenkins GP, Connolly RM (2010) Resource distribution influences positive edge effects in a seagrass fish. Ecology 91:2013-2021

Micheli F, Peterson CH (1999) Estuarine vegetated habitats as corridors for predator movements. Conserv Biol 13: 869-881

> Micheli F, Bishop MJ, Peterson CH, Rivera J (2008) Alteration of seagrass species composition and function over two decades. Ecol Monogr 78:225-244

Murdoch WW (1969) Switching in general predators: experiments on predator specificity and stability of prey populations. Ecol Monogr 39:335-354

> Myers RA, Baum JK, Shepherd TD, Powers SP, Peterson CH (2007) Cascading effects of the loss of apex predatory sharks from a coastal ocean. Science 315:1846-1850

O'Connor NE, Grabowski JH, Ladwig LM, Bruno JF (2008) Simulated predator extinctions: predator identity affects survival and recruitment of oysters. Ecology 89:428-438

Paine RT (1966) Food web complexity and species diversity. Am Nat 100:65-75

Peterson CH, Ambrose WG, Hunt JH (1982) A field test of the swimming response of the bay scallop (Argopecten irradians) to changing biological factors. Bull Mar Sci 32: 939-944

> Peterson CH, Grabowski JH, Powers SP (2003) Estimated enhancement of fish production resulting from restoring oyster reef habitat: quantitative valuation. Mar Ecol Prog Ser 264:249-264

> Powers SP, Peterson CH (2000) Conditional density dependence: the flow trigger to expression of density-dependent emigration in bay scallops. Limnol Oceanogr 45:727-732

Quinn GP, Keough MJ (2002) Experimental design and data analysis for biologists. Cambridge University Press, Cambridge

Rothschild BJ, Ault JS, Goulletquer P, Heral M (1994) Decline of the Chesapeake oyster population: a century of habitat destruction and overfishing. Mar Ecol Prog Ser 111:29-39

> Shervette VR, Perry HM, Rakocinski CF, Biesiot PM (2004) Factors influencing refuge occupation by stone crab Menippe adina juveniles in Mississippi Sound. J Crustac Biol 24:652-665

Smith GF, Bruce DG, Roach EB, Hansen A, Newell RTE, McManus AM (2005) Assessment of recent habitat conditions of eastern oyster Crassostrea virginica bars in mesohaline Chesapeake Bay. N Am J Fish Manag 25: 1569-1590

> Warry FY, Hindell JS, Macreadie PI, Jenkins GP, Connolly RM (2009) Integrating edge effects into studies of habitat fragmentation: a test using meiofauna in seagrass. Oecologia 159:883-892

Wong MC, Peterson CH, Kay J (2010) Prey size selection and bottom type influence multiple predator effects in a crab-bivalve system. Mar Ecol Prog Ser 409:143-158

> Zohar Y, Hines AH, Zmora O, Johnson EG and others (2008) The Chesapeake Bay blue crab (Callinectes sapidus): a multidisciplinary approach to responsible stock replenishment. Rev Fish Sci 16:24-34

Submitted: August 19, 2010; Accepted: March 2, 2011

Proofs received from author(s): May 6, 2011 